\title{
The effectiveness and value of belimumab and voclosporin for lupus nephritis
}

\author{
A summary from the Institute for Clinical and Economic Review's New England Comparative \\ Effectiveness Public Advisory Council
}

Jeffrey A Tice, MD; Olena Mandrik, PhD, MSc; Praveen Thokala, PhD, MASc; James Fotheringham, MD, PhD;

and Steven D Pearson, MD, MSc

Systemic lupus erythematosus (SLE) is an autoimmune disease that affects between 300,000 and 1.5 million Americans. ${ }^{1}$ It is more common in women (90\% of diagnosed cases) and in non-Whites (4 times higher prevalence in Black patients; 2 times higher prevalence in Hispanic patients). Approximately half of patients with SLE will be diagnosed with lupus nephritis (LN), characterized by inflammation in the kidney, proteinuria, and progressive kidney damage that can lead to kidney failure., ${ }^{2,3} \mathrm{LN}$ typically presents in patients who are aged 20-40 years, 4,5 and it is the most common cause of death and disability in patients with SLE.

Guidelines for the treatment of LN recommend induction therapy with high-dose corticosteroids combined with either mycophenolate mofetil (MMF) or cyclophosphamide, followed by maintenance therapy with MMF.,7 Unfortunately, fewer than half of patients with LN respond to current combination therapy, so there is a large unmet need for new therapies.

The US Food and Drug Administration (FDA) recently approved 2 new therapies for LN. Belimumab, a parenteral B-lymphocyte inhibitor already approved by the FDA for SLE, was approved for $\mathrm{LN}$ in December 2020. Voclosporin, an oral calcineurin inhibitor that is reported to be safer than other calcineurin inhibitors (less kidney damage), was approved in January 2021.

The Institute for Clinical and Economic Review (ICER) conducted a systematic literature review and cost-effectiveness analysis to evaluate the health and economic outcomes of belimumab and voclosporin to treat LN. Complete details of ICER's systematic literature search and protocol, as well as the methodology and model structure for the economic evaluation, are available on ICER's website. Here, we present the summary of our findings and highlights of the policy discussion with key stakeholders held at a public meeting of the New England Comparative Effectiveness Public Advisory Council on March 26, 2021. The detailed report is available on the ICER website at https://icer. org/wp-content/uploads/2020/11/ ICER Lupus-Nephritis_FinalEvidence-Report_041621.pdf.

\section{Summary of Findings}

\section{CLINICAL EFFECTIVENESS}

Belimumab increased the complete renal response (CRR) and primary efficacy renal response (PERR) at 2 years compared with standard therapy alone, with benefits seen after the first year and appearing stable at year 2 (see Table 1 for outcome definitions). ${ }^{8}$ At 2 years, the proportion of patients

\author{
Author affiliations \\ Jeffrey A Tice, MD, Division of General \\ Internal Medicine, University of \\ California, San Francisco. Olena Mandrik, \\ PhD, MSc; Praveen Thokala, PhD, MASc; \\ and James Fotheringham, MD, PhD, \\ Health Economics and Decision Science \\ (HEDS), School of Health and Related \\ Research (ScHARR), The University of \\ Sheffield, United Kingdom. Steven D \\ Pearson, MD, MSc, Institute for Clinical \\ and Economic Review, Boston, MA. \\ AUTHOR CORRESPONDENCE: \\ Jeffrey A Tice, jeff.tice@ucsf.edu \\ J Manag Care Spec Pharm. \\ 2021;27(10):1495-99 \\ Copyright $@ 2021$, Academy of Managed \\ Care Pharmacy. All rights reserved.
}

receiving $5 \mathrm{mg}$ or less of prednisone was also greater in the belimumab group (36.8\% vs $27.8 \%$ ). There were no significant increases in adverse events or discontinuations compared with standard induction therapy for LN.

Voclosporin nearly doubled complete response (CR) and markedly increased the partial response (PR) at 1 year compared with standard 


\begin{tabular}{|c|c|c|c|}
\hline & Outcome $^{a}$ & Urine protein creatinine ratio, $\mathrm{mg} / \mathrm{mg}$ & $\begin{array}{l}\text { Estimated glomerular filtration rate, } \\
\mathrm{ml} \text { per minute per } 1.73 \mathrm{~m}^{2}\end{array}$ \\
\hline BLISS LN trial & Complete renal response (CRR) & $<0.5$ & $\geq 90$ or $\geq 90 \%$ baseline \\
\hline (Belimumab) & Primary efficacy renal response (PERR) & $\leq 0.7$ & $>60$ or $\geq 80 \%$ baseline \\
\hline AURORA trial & Complete renal response (CR) & $\leq 0.5$ & $\geq 60$ or $\geq 80 \%$ baseline \\
\hline (Voclosporin) & Partial renal response (PR) & $\geq 50 \%$ reduction from baseline & - \\
\hline
\end{tabular}

\section{TABLE 2 Model Results for Belimumab and Voclosporin Compared with Standard Care}

\begin{tabular}{|c|c|c|c|c|c|}
\hline \multirow[b]{2}{*}{ Deterministic analysis } & \multirow[b]{2}{*}{ Total costs } & \multirow[b]{2}{*}{ QALYs } & \multirow[b]{2}{*}{ LYs } & \multicolumn{2}{|c|}{ Incremental results } \\
\hline & & & & Cost/QALY gained & Cost/LY gained \\
\hline \multicolumn{6}{|c|}{ Comparison of belimumab with standard care } \\
\hline Belimumab & $\$ 929,962$ & 11.666 & 17.861 & $\$ 89,663$ & $\$ 113,847$ \\
\hline Standard care & $\$ 886,343$ & 11.180 & 17.478 & - & - \\
\hline \multicolumn{6}{|c|}{ Comparison of voclosporin with standard care } \\
\hline Belimumab & $\$ 928,486$ & 12.640 & 18.408 & $\$ 149,260$ & $\$ 174,250$ \\
\hline Standard care & $\$ 784,416$ & 11.674 & 17.581 & - & - \\
\hline
\end{tabular}

$L Y=$ life-year; $Q A L Y=$ quality-adjusted life-year.

therapy alone (Table 1). ${ }^{9}$ The proportion of patients able to be maintained on lower steroid doses was not reported, but all those with PR and CR were required to be taking low-dose steroids. Adverse events were comparable to standard induction therapy for LN, but the FDA added a black box warning consistent with that of cyclosporin, another calcineurin inhibitor, for possible serious infections and malignancies.

\section{LIMITATIONS OF THE CLINICAL EVIDENCE}

The most important uncertainty is how these short-term rates of partial and complete renal response translate into meaningful long-term outcomes for patients. LN is a lifethreatening, lifelong illness, and the outcomes that matter most to patients are progression to kidney failure or death. It is also unclear from the available evidence how long therapy with these novel agents should continue. Finally, LN disproportionately affects non-White patients. The number of non-White patients enrolled by drug makers in pivotal trials was too small to determine relative effectiveness of either drug across racial and ethnic groups, which is important given the greater prevalence and severity of LN in non-White populations, as well as their lower response rate to conventional induction therapy.

\section{LONG-TERM COST-EFFECTIVENESS}

The cost-effectiveness analyses compared each drug to standard of care as delivered within the comparator arm in each of the pivotal trials. The model consisted of 2 parts: a short-term model concordant with data from the clinical trials, which feeds into a lifetime model using partitioned survival modeling based on long-term outcomes studies of patients with LN. A detailed description of the model can be found in the full report (https://icer.org/wp-content/ uploads/2020/11/ICER_Lupus-Nephritis_Final-EvidenceReport_041621.pdf).

Treatment costs were calculated using the average sales price for intravenous belimumab (\$46.38 per $10 \mathrm{mg}$ ) and mean dose of $690 \mathrm{mg}$ (estimated using the dose of $10 \mathrm{mg}$ per kilogram of body weight and the distribution of the body weights of the LN population retrieved from the literature, accounting for vial wastage). Voclosporin costs were estimated using price per wallet (\$3,950 per 60 capsules $7.9 \mathrm{mg}$ each) and average daily dose of $39.1 \mathrm{mg}$ (mean dose 


\section{TABLE 3 Votes on Contextual Considerations and Potential Other Benefits or Disadvantages} for Any Effective Treatment for Lupus Nephritis

\begin{tabular}{|c|c|c|c|c|c|}
\hline & $\begin{array}{l}\text { Very low } \\
\text { priority }\end{array}$ & Low priority & $\begin{array}{l}\text { Average } \\
\text { priority }\end{array}$ & High priority & $\begin{array}{l}\text { Very high } \\
\text { priority }\end{array}$ \\
\hline Short-term risk of death for patients without treatment & 4 & 6 & 2 & 0 & 0 \\
\hline $\begin{array}{l}\text { Magnitude of the lifetime effect on individual patients of the } \\
\text { condition being treated }\end{array}$ & 0 & 0 & 0 & 4 & 8 \\
\hline
\end{tabular}

\section{TABLE 4 Votes on Contextual Considerations and Potential Other Benefits or Disadvantages for Belimumab vs Usual Care}

\begin{tabular}{|c|c|c|c|c|c|}
\hline \multicolumn{6}{|c|}{$\begin{array}{l}\text { What are the relative effects of belimumab vs standard induction therapy for lupus nephritis on the } \\
\text { following outcomes that inform judgement of the overall long-term value for money of belimumab? }\end{array}$} \\
\hline & $\begin{array}{c}\text { Major } \\
\text { negative } \\
\text { effect }\end{array}$ & $\begin{array}{c}\text { Minor } \\
\text { negative } \\
\text { effect }\end{array}$ & $\begin{array}{l}\text { No } \\
\text { difference }\end{array}$ & $\begin{array}{l}\text { Minor } \\
\text { positive } \\
\text { effect }\end{array}$ & $\begin{array}{c}\text { Major } \\
\text { positive } \\
\text { effect }\end{array}$ \\
\hline $\begin{array}{l}\text { Patients' ability to achieve major life goals related to education, } \\
\text { work, or family life }\end{array}$ & 0 & 0 & 2 & 4 & 6 \\
\hline $\begin{array}{l}\text { Caregivers' quality of life and/or ability to achieve major life goals } \\
\text { related to education, work, or family life }\end{array}$ & 0 & 0 & 2 & 7 & 3 \\
\hline The problem of health inequity & 0 & 0 & 2 & 6 & 4 \\
\hline $\begin{array}{l}\text { Other (as relevant): Preservation of kidney function improves the } \\
\text { chances for patients to have children }\end{array}$ & 0 & 0 & 2 & 5 & 5 \\
\hline
\end{tabular}

weighted to the duration of patients in the AURORA trial), using a $22.5 \%$ discount. It was assumed that patients in response states remain on the therapy for 3 years.

In the base case (Table 2), the incremental cost-effectiveness ratio for belimumab was estimated to be approximately $\$ 90,000$ per quality-adjusted life-year (QALY), and $\$ 78,000$ per equal value of life-years gained (evLYG). The corresponding results for voclosporin were approximately $\$ 149,000$ per QALY and $\$ 132,000$ per evLYG. In 1-way sensitivity analyses, the incremental cost-effectiveness ratios were most sensitive to the monthly costs for patients with active kidney disease and the utilities for the active disease and complete response health states. In probabilistic sensitivity analyses, belimumab was cost effective at the $\$ 150,000$ per QALY threshold in $69 \%$ of the runs and voclosporin in $49 \%$ of the runs.

\section{LIMITATIONS OF THE COST-EFFECTIVENESS MODEL}

There are no long-term follow-up data for either treatment, resulting in considerable uncertainty about the prognosis of patients beyond the trial periods. Robust utility data were lacking for patients with $\mathrm{LN}$ in the United States across the health states in the model, so data from other populations were used.

\section{Policy Discussion}

The New England Comparative Effectiveness Public Advisory Council (CEPAC) is one of the independent appraisal committees convened by ICER to engage in public deliberation of the evidence on clinical and cost-effectiveness of health care interventions. The New England CEPAC is composed of medical evidence experts, including practicing clinicians, methodologists, and leaders in patient engagement and advocacy. Their deliberation includes input from clinical experts and patient representatives specific to the condition under review, as well as formal comment from manufacturers and the public. A policy roundtable concludes each meeting during which representatives from insurers and manufacturers join clinical experts and patient representatives to discuss how best to apply the findings of the evidence to clinical practice, insurance coverage, and pricing negotiations. 


\section{TABLE 5 Votes on Contextual Considerations and Potential Other Benefits or Disadvantages for Voclosporin vs Usual Care}

\begin{tabular}{|c|c|c|c|c|c|}
\hline \multicolumn{6}{|c|}{$\begin{array}{l}\text { What are the relative effects of voclosporin vs standard induction therapy for lupus nephritis on the } \\
\text { following outcomes that inform judgement of the overall long-term value for money of voclosporin? }\end{array}$} \\
\hline & $\begin{array}{c}\text { Major } \\
\text { negative } \\
\text { effect }\end{array}$ & $\begin{array}{c}\text { Minor } \\
\text { negative } \\
\text { effect }\end{array}$ & $\begin{array}{l}\text { No } \\
\text { difference }\end{array}$ & $\begin{array}{l}\text { Minor } \\
\text { positive } \\
\text { effect }\end{array}$ & $\begin{array}{c}\text { Major } \\
\text { positive } \\
\text { effect }\end{array}$ \\
\hline $\begin{array}{l}\text { Patients' ability to achieve major life goals related to education, } \\
\text { work, or family life }\end{array}$ & 0 & 0 & 2 & 5 & 5 \\
\hline $\begin{array}{l}\text { Caregivers' quality of life and/or ability to achieve major life goals } \\
\text { related to education, work, or family life }\end{array}$ & 0 & 0 & 2 & 7 & 3 \\
\hline The problem of health inequity & 0 & 0 & 1 & 7 & 4 \\
\hline $\begin{array}{l}\text { Other (as relevant): Preservation of kidney function improves the } \\
\text { chances for patients to have children }\end{array}$ & 0 & 0 & 2 & 5 & 5 \\
\hline
\end{tabular}

The ICER report on new therapies for LN was the subject of a New England CEPAC meeting on March 26, 2021. Following the discussion, the New England CEPAC panel members deliberated on key questions raised by ICER's report. The results of their votes on the clinical evidence were as follows: (1) the panel voted 12-0 that the clinical evidence was adequate to demonstrate greater net health benefit for belimumab plus standard therapy compared with standard therapy alone and (2) the panel voted 12-0 that the clinical evidence was adequate to demonstrate greater net health benefit for voclosporin plus standard therapy compared with standard therapy alone.

The CEPAC panel also voted on "other potential benefits" and "contextual considerations" as part of a process intended to signal to policymakers whether there are important considerations when making judgments about long-term value for money not adequately captured in analyses of clinical and/or cost-effectiveness. The results of these votes are shown in Tables 3-5. They highlight several factors beyond the results of cost-effectiveness modeling that the CEPAC panel felt were particularly important for judgments of overall long-term value for money.

As described in ICER's Value Assessment Framework, questions on long-term value for money are subject to a value vote when incremental cost-effectiveness ratios for the interventions of interest are between $\$ 50,000$ and $\$ 175,000$ per QALY in the primary base-case analysis. Nine members of the 12 CEPAC panel voted that belimumab at the current discounted price represented high value for the money; 2 voted that it represented intermediate value; and 1 voted that it represented low long-term value for the money. Four members of the CEPAC voted that voclosporin at the current discounted price represented high value for money; 7 voted that it represented intermediate value; and 1 voted that it represented low long-term value for the money.

The policy roundtable discussion explored how best to translate the evidence and additional considerations into clinical practice and into pricing and insurance coverage policies. The full set of policy recommendations can be found in the Final Evidence Report on the ICER website: https://icer.org/wp-content/uploads/2020/11/ ICER_Lupus-Nephritis_Final-Evidence-Report_041621. pdf. Several key policy recommendations for the new treatments for LN follow:

- Both belimumab and voclosporin are judged to be priced in reasonable alignment with estimates of their benefits for patients, and this consideration should guide payers to design coverage criteria that do not narrow coverage from the FDA label, although coverage criteria may define terms left indeterminate in the FDA label to assure appropriate use. Given the significant uncertainty that remains about the longer-term safety and effectiveness of belimumab and voclosporin for lupus nephritis, it is reasonable for payers to use prior authorization as a component of coverage.

- All stakeholders have a responsibility and an important role to play in ensuring that effective new treatment options for patients with lupus nephritis are introduced in a way that will help reduce health inequities. People from diverse racial and ethnic backgrounds are at a higher risk of developing lupus and lupus nephritis. Unfortunately, patients from these communities are also at a higher risk of not receiving adequate education about their condition, face a longer time between diagnosis to initiation of any therapy, and are often late to receive guidance 
regarding new treatment options. All stakeholders should accept and act upon their responsibility to address these disparities.

- For voclosporin, given the FDA label language based on the potential for nephrotoxicity with prolonged use, physician attestation of a response to therapy of at least a $50 \%$ reduction in proteinuria after 6-12 months of therapy is not unreasonable. Current data support 1 year of therapy, but clinical experts and some trial data suggest that longer treatment duration may be appropriate in individual patients.

\section{DISCLOSURES}

Funding for this summary was contributed by Arnold Ventures, California Health Care Foundation, The Donaghue Foundation, Harvard Pilgrim Health Care, and Kaiser Foundation Health Plan to the Institute for Clinical and Economic Review (ICER), an independent organization that evaluates the evidence on the value of health care interventions.

ICER's annual policy summit is supported by dues from AbbVie, Aetna, America's Health Insurance Plans, Anthem, Alnylam, AstraZeneca, Biogen, Blue Shield of CA, Boehringer-Ingelheim, Cambia Health Services, CVS, Editas, Evolve Pharmacy, Express Scripts, Genentech/Roche, GlaxoSmithKline, Harvard Pilgrim, Health Care Service Corporation, HealthFirst, Health Partners, Humana, Johnson \& Johnson (Janssen), Kaiser Permanente, LEO Pharma, Mallinckrodt, Merck, Novartis, National Pharmaceutical Council, Pfizer, Premera, Prime Therapeutics, Regeneron, Sanofi, Spark Therapeutics, uniQure, and United Healthcare.

Pearson is employed by ICER. Through their affiliated institutions, Tice, Mandrik, Thokala, and Fotheringham received funding from ICER for the work described in this summary.

\section{ACKNOWLEDGMENTS}

The authors thank Foluso Agboola, Serina Herron-Smith, and Rick Chapman for their contributions to this report.

\section{REFERENCES}

1. Medline Plus. Systemic lupus erythematosis. US National Library of Medicine. Updated August 18, 2020. Accessed August 30, 2020. https://ghr.nlm.nih.gov/ condition/systemic-lupus-erythematosus

2. Albuquerque BC, Salles VB, Tajra RDP, Rodrigues CEM. Outcome and prognosis of patients with lupus nephritis submitted to renal transplantation. Sci Rep. 2019;9(1):11611.

3. Jaryal A, Vikrant S. Current status of lupus nephritis. Indian J Med Res. 2017;145(2):167-78.

4. Carls G, Li T, Panopalis P, et al. Direct and indirect costs to employers of patients with systemic lupus erythematosus with and without nephritis. J Occup Environ Med. 2009;51(1):66-79.

5. Feldman CH, Broder A, Guan H, Yazdany J, Costenbader KH. Sex differences in health care utilization, end-stage renal disease, and mortality among Medicaid beneficiaries with incident lupus nephritis. Arthritis Rheumatol. 2018;70(3):417-26.
6. Fanouriakis A, Kostopoulou M, Cheema K, et al. 2019 Update of the Joint European League Against Rheumatism and European Renal Association-European Dialysis and Transplant Association (EULAR/ERA-EDTA) recommendations for the management of lupus nephritis. Ann Rheum Dis. 2020;79(6):713-23.

7. Hahn BH, McMahon MA, Wilkinson A, et al. American College of Rheumatology guidelines for screening, treatment, and management of lupus nephritis. Arthritis Care Res (Hoboken). 2012;64(6):797-808.

8. Furie R, Rovin BH, Houssiau F, et al. Two-year, randomized, controlled trial of belimumab in lupus nephritis. N Engl J Med. 2020;383(12):1117-28.

9. Rovin BH, Teng YKO, Ginzler EM, et al. Efficacy and safety of voclosporin versus placebo for lupus nephritis (AURORA 1): a double-blind, randomised, multicentre, placebo-controlled, phase 3 trial. Lancet. 2021;397(10289):2070-80. 